\title{
Experimental Value of Representative Models in Wooden Constructions
}

\author{
Fabio Bianconi \\ Marco Filippucci \\ Giulia Pelliccia
}

\section{Abstract}

Drawing has always been a necessary model for directing architectural realization. The design of the shape has become a nodal condition for multiple analysis integration, which is increasingly necessary to meet the performance requirements to which the design must react holistically as a result of digital representation, which has resulted in the enrichment and sophistication of the simulation's predictive capacity. The aim of the study is to test the theories that have been proposed and to ensure that the results are accurate. It is important to test the accuracy of the adopted solutions using the models themselves, through the use of an empirical approach that must be abstracted into a constructed representation capable of synthesizing the qualities to be detected. The current research, which has resulted in the development of some case studies in the field of wooden constructions, is set in a framework that emphasizes the relationship between simulation and realization.

\section{Keywords}

multi-objective optimization, digital simulation, wooden structures, generative algorithms, parametric design.

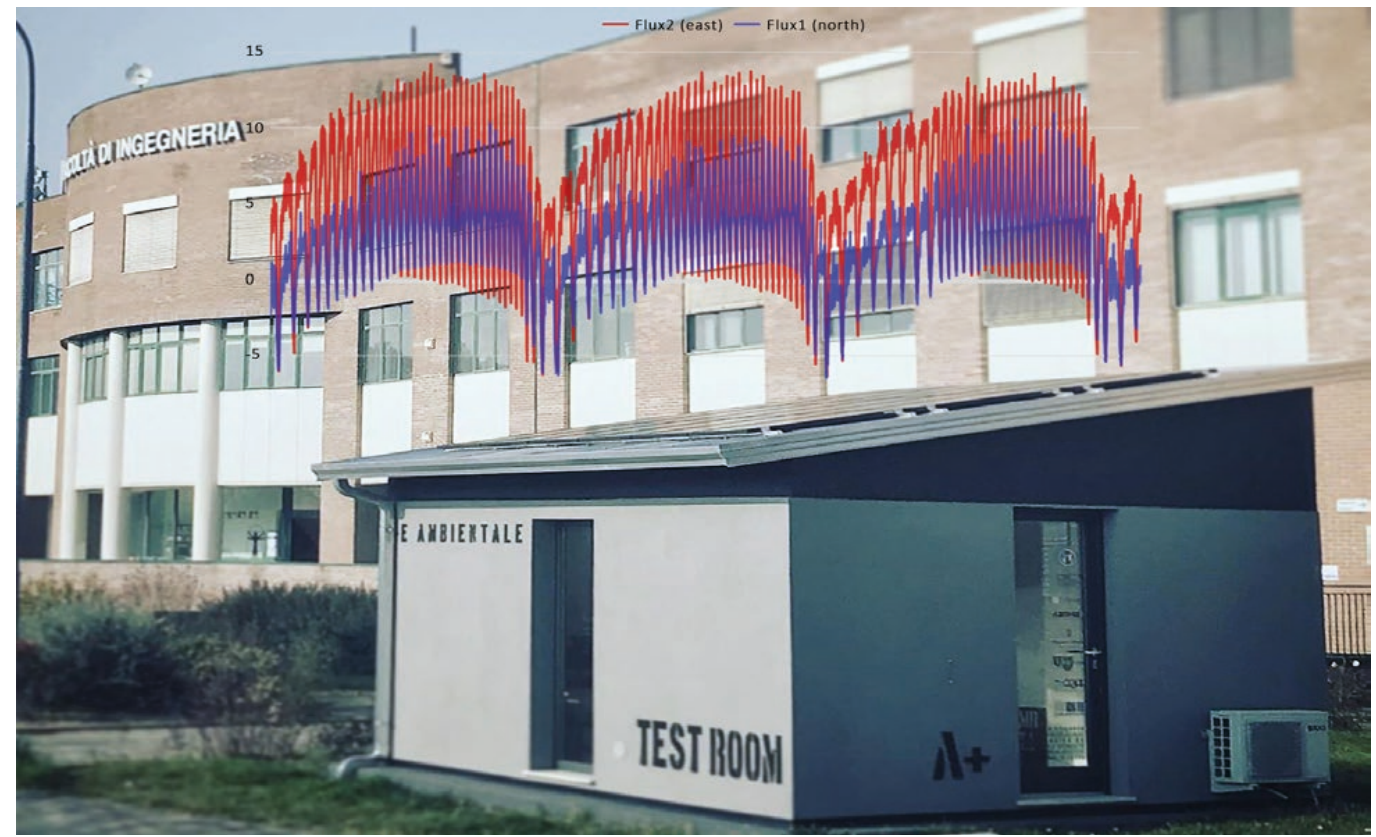




\section{Introduction}

The importance of representation as a model-building site is focused on the digitization process and the convergence of the different aspects of the form into digital computational tools. Models gather and analyze data and information through interconnected and interdisciplinary routes in order to turn them into knowledge. Due to its transdisciplinary nature, representation becomes the language of knowledge incorporation, introducing its own field of experimental and heuristic intervention, with paths that must be validated.

The research, which was formed as part of a collaboration between the Department of Civil and Environmental Engineering and Abitare+, a local creative wood construction start-up, provided an opportunity to put in place a direction that aimed to achieve these objectives of innovation and knowledge transfer. Simultaneously, joint competencies have been developed to kick-start product and service innovation processes. The analysis of generative models aimed at multi-optimizing the form, energy efficiency, structure, and cost of wooden houses leads to the integration with BIM models. To encourage this practice, an Ames room has been developed with a high media impact to highlight the proposed creative approach. The study then moved on to multi-optimization of wooden structural walls from this first direction. Simultaneously, a study of a new 'breathing house' model was conducted, applying responsive solutions to indoor hygrometric changes. To check the validity of such solutions, a test room was built as an abstract representation of a wooden house reduced to the size of a paradigmatic room.

Generative modeling, BIM, and software solutions unique to the various disciplines involved are useful tools to integrate architectural, representative, positive, resources, and communication aspects. Once ready for the industrialization process, the models, which in this case are materialized in a physical form (the model of the model), must be tested.

\section{The Research Path}

The analysis of generative models [Bianconi, Filippucci, Buffi 20।7; Filippucci 20I2] is followed by a proposal for an integrated mass customization-based design and production process [Duarte 2005; Paoletti 20 17], which is aimed primarily at wood construction technicians and specialists but also useful as a dissemination tool for students and researchers. The study looks into the possibility of using generative models and evolutionary principles to inform the design and customization process. The first case study [Bianconi, Filippucci 2019] aims to provide individualized housing designs to central Italy.

These square-plan houses, designed as modular solutions that can be transported and assembled easily following a simple manufacturing process, can be combined to build custom multi-family homes and villages that conform to both the environment and their inhabitants. The generative process specifies a variety of design options, all of which depend on genetic algorithms to adapt and optimize the architectural model. The design concept is focused on the analysis of local codes and X-Lam and Platform-Frame building systems with the goal of reducing waste and optimizing the construction process. With the study's goal in mind, energy consumption, thermal, and visual comfort, as well as price, were evaluated with the construction company and through iterative processes. The results of this first study, which began with the selection of solutions available to the company, have prompted a closer examination of each element that makes up the envelope.

The realization of the Ames room is exemplary in this regard [Ames, Ittelson 1952]. It is an application of perceptual theories [Arnheim 1965; Gibson 2018] that reviews digital algorithms to concretize an architectural expedient based on image culture [Pinotti, Somaini Elcograf 20 I6] and that has led to a model that synthesizes the research's multiple questions [Bianconi, Filippucci 2020].

The focus of the investigation then shifted to improving the energy efficiency of wooden structures that had previously been customized to meet the location's specific requirements. The aim in this case is to use generative design tools to optimize the preliminary cost and efficiency of wood walls for X-Lam and Platform-Frame structures, with the goal 
of evaluating the actual performance of the built solutions [Seccaroni, Pelliccia 2019]. As a result, the described workflow begins with the implementation of parametric algorithms in Grasshopper that return thermal transmittance, decrement factor, time shift, costs, and verify the absence of interstitial condensation while varying the wall materials and thicknesses from time to time [Aste et al. 20 I5; Rossi, Rocco 20 I4]. The selected parameters can be processed in a multi-optimization direction based on the application of evolutionary principles through the Grasshopper plug-in Octopus [Diakaki, Grigoroudis, Kolokotsa 2008], in which more than 5000 possible material and thicknesses combinations have been automatically analyzed.
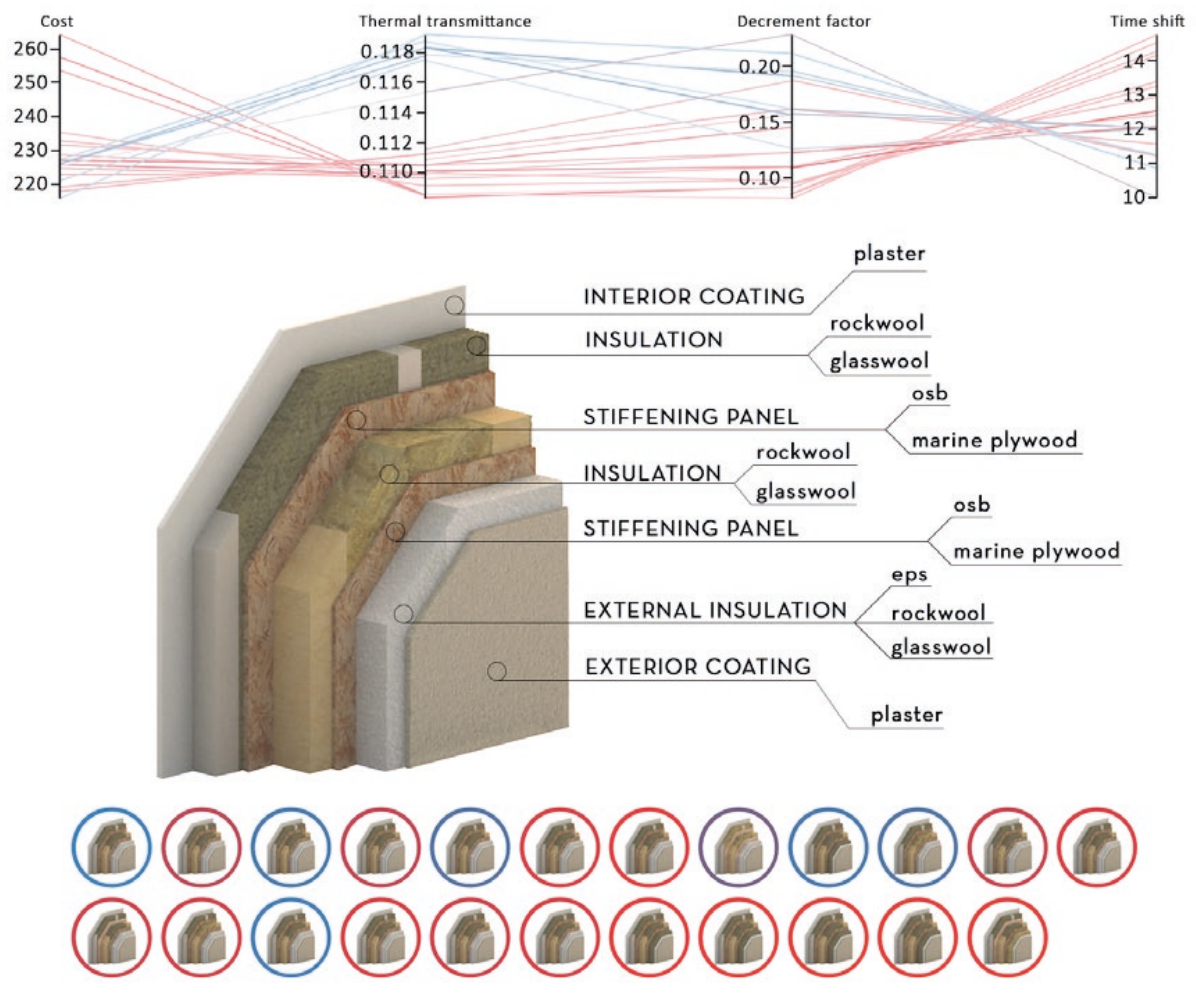

The best solutions can thus be selected, identifying the Pareto front [Wang, Zmeureanu, Rivard 2005; Wright et al. 2002], in which the combinations simultaneously present optimal values of the various parameters that evaluate the wall's summer and winter behavior, as well as the overall cost (fig. I). Because of Octopus' genetic multi-optimization, the approach just mentioned is based on the development of an algorithm capable of simulating human decisions in finding the most suitable solutions from both an energy and economic standpoint. As a consequence, the algorithm acts as an Artificial Intelligence (Al) [Ridolfi, Saberi 2019] because it simulates human decision-making and also allows for the testing of a wide number of potential combinations. The research then moved from virtual to physical with the construction of a test space. The test room is an abstract representation of a wooden house scaled down to a paradigmatic space's dimension. It stands out thanks to a removable wall that can be replaced with any kind of X-Lam or Platform-Frame construction. This architectural aspect was realized with one of the walls optimized by the algorithm and was monitored once fitted with sensors and data acquisition systems to compare the data obtained from simulations with the real ones and thus understand the actual usefulness of the optimization tools used. The in situ transmittance was calculated using thermocouples, flux meters, and additional temperature and humidity probes, and compared to the algorithm simulation using UNI ISO 9869 [ISO 9869-1:20I4Thermal Insulation - Building 
Fig. 2. Thermocouples, fluxmeters, temperature and humidity probes and anemometers inside the test room.
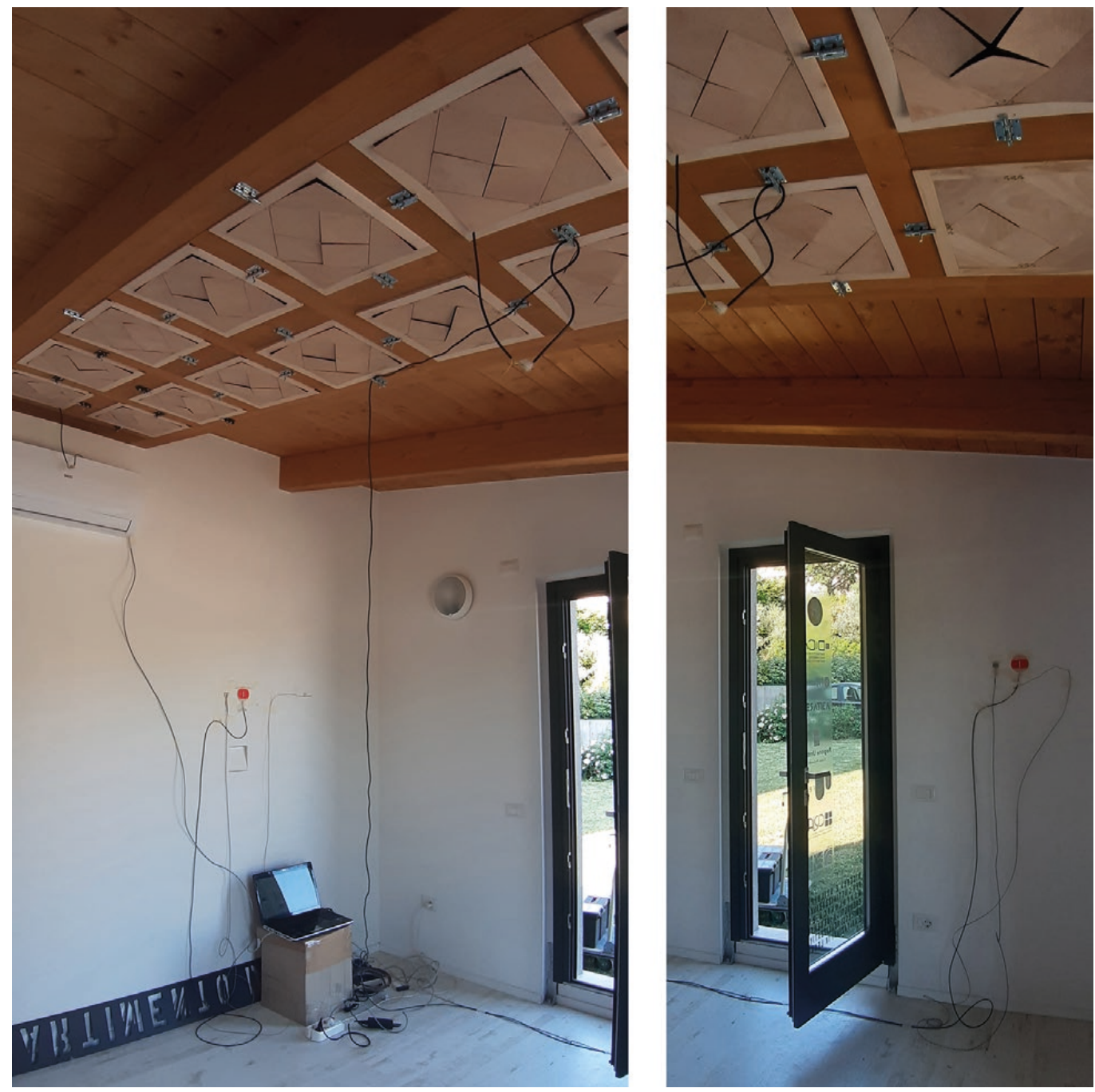

Elements - In-Situ Measurement of Thermal Resistance and Thermal Transmittance - Part I: Heat Flow Meter Method 20I4]. The obtained results confirm the simulated model's consistency with the structure's actual behavior, taking into account a percentage of error due to various factors that may affect field measurements (fig. 2).

\section{Conclusions}

The relationship between digital and wooden constructions opens up impressive fields of use, as shown by the integrated action promoted by an international call [Bianconi, Filippucci 2019b]. It has also led to the development of a research network involving more than 150 researchers from all continents [Bianconi, Filippucci 2019a]. The great cultural value of this initiative can be ascribed to the new key role of representation for contemporary research. The research outlined the value of preliminary digital simulation for form-finding, both in terms of the project's actual final configuration and in terms of the less tangible aspects of the building's efficiency. As a result, representation takes on a new position as the 'place' of the model. The dynamic passage between real and virtual in a spatial model helps in representing intangibly, with high reliability, what is concretely abstract.This demonstrates the representative models' experimental importance. By using artificial intelligence's analytical capabilities and reinterpreting the flow of data collected during the monitoring, the study aims to define and validate the best performing solutions for the particular architectural project. 


\section{References}

Ames Adelbert, Ittelson William H. (1952). The Ames Demonstrations in Perception. New York: Hafner Publishing.

Arnheim Rudolf (1965). Art and visual perception: A psychology of the creative eye. Los Angeles: University of California Press.

Aste Niccolò, Leonforte Fabrizio, Manfren Massimiliano, Mazzon Manlio (2015). Thermal inertia and energy efficiency Parametric simulation assessment on a calibrated case study. In Applied Energy, | 45, pp. I | I - I 23.

Bianconi Fabio, Filippucci Marco (eds.) (2019a). Digital Wood Design. Innovative Techniques of Representation in Architectural Design, 24.

Bianconi Fabio, Filippucci Marco (20/9b). Digital Wood Design. Tecniche innovative di rappresentazione nella progettazione architettonica. In Bertocci Stefano, Conte Antonio (eds.) II Simposio UID di internazionalizzazione della ricerca. Patrimoni culturali, Architettura, Paesaggio e Design tra ricerca e sperimentazione didattica. Firenze: Didapress, pp. 326-329.

Bianconi Fabio, Filippucci Marco (2020). Disegnare la Camera di Ames. Le questioni architettoniche, le lezioni del classico, le sperimentazioni digitali. In Disegnare. Idee Immagini, 60, pp. 50-6I.

Bianconi Fabio, Filippucci Marco, Buffi Alessandro (2017). Disegno, modello, natura. II form-finding dopo I00 anni di "Crescita e forma." In 3D MODELING \& BIM. Roma: DEl, pp. 398-4I3.

Bianconi Fabio, Filippucci Marco, Buffi Alessandro (2019). Automated design and modeling for mass-customized housing. A web-based design space catalog for timber structures. In Automation in Construction, 103.

Diakaki Christina, Grigoroudis Evangelos, Kolokotsa Dionyssia (2008). Towards a multi-objective optimization approach for improving energy efficiency in buildings. In Energy and Buildings, 40 (9), pp. I 747- 1754.

Duarte José P. (2005). A discursive grammar for customizing mass housing: the case of Siza's houses at Malagueira. In Automation in Construction, 14 (2), pp. 265-275.

Filippucci Marco (20 I2). Rappresentazione al quadrato. II disegno generativo per il rinnovamento della geometria descrittiva In Carlevalis Laura, De Carlo Laura, Migliari Roberto (eds.), Attualità della Geometria Descrittiva Seminario nazionale sul rinnovamento della Geometria descrittiva. Roma: Gangemi.

Gibson James J. (20 I 8). The Ecological Approach to Visual Perception. London: Psychology Press, 2018. https://doi.org/I0.2307/j. $\mathrm{ctt} \mid \times \mathrm{xp} 3 \mathrm{nmm} .20$

ISO 9869-1:2014 (2014). Thermal insulation - Building elements - In-situ measurement of thermal resistance and thermal transmittance - Part I: Heat flow meter method.

Paoletti Ingrid (2017). Mass customization in the era of industry 4.0: Towards immaterial building technology. In Informed Architecture: Computational Strategies in Architectural Design. Cham, Switzerland AG; Springer International Publishing, pp. 77-87.

Pinotti Andrea., Somaini Antonio, Elcograf Cles (2016). Cultura visuale: immagini sguardi media dispositivi. Segrate: Einaudi.

Ridolfi Giuseppe, Saberi Arman (2019). Intelligenze Computazionali nel Progetto post-Ambientale Computational Intelligences in the post-Environmental Design RIDOLFI. In International Journal of Architecture, Art and Design, 5, pp. 31-40.

Rossi Monica, Rocco Valeria Marta (2014). External walls design:The role of periodic thermal transmittance and internal areal heat capacity. In Energy and Buildings, 68, pp. 732-740.

Seccaroni Marco, Pelliccia Giulia (2019). Customizable social wooden pavilions: A workflow for the energy, emergy and perception optimization in perugia's parks. In Bianconi Fabio, Filippucci Marco (eds.). Digital Wood Design. Innovative Techniques of Representation in Architectural Design, 24, pp. 1045 - 1062

Wang Weimin, Zmeureanu Radu, Rivard Hugues (2005). Applying multi-objective genetic algorithms in green building design optimization. In Building and Environment, 40 (I I), pp. I5 I2- I525.

Wright Jonathan A., Loosemore Heather A., Farmani Raziyeh (2002). Optimization of building thermal design and control by multi-criterion genetic algorithm. In Energy and Buildings, 34 (9), pp. 959-972.

\section{Authors}

Fabio Bianconi, Dept.of Civil and Environmental Engineering, University of Perugia, fabio.bianconi@unipg.it

Marco Filippucci, Dept. of Civil and Environmental Engineering, University of Perugia, marco.filippucci@unipg.it

Giulia Pelliccia, Dept. of Civil and Environmental Engineering, University of Perugia, giulia.pelliccia@outlook.it 
